conserving technologies in an area where vegetable production traditionally involves high inputs. This can have long-term ecological, socioeconomic, and public health ramifications, but such benefits will become more apparent as the conversion process from high-input to low-input agriculture continues.

As the effects of biological pest control and organic amendments become more evident, we expect that farmers adopting the new systems will beable to reduce energy use, cut costs of production and secure diversity of production for subsistence and marketing. In fact, we expect that the maximum yields sustained by organic methods could be much higher than those now realized. Indirect benefits may include reduced soil erosion, reduced chemical pollution, better water conservation, and increased soil biological activity.

As our collaborating small farmers link to specialty and natural food markets with products either certified as organic or perceived as chemical-free, they will enhance their ability to obtain premium prices for their produce, considerably increasing income.

This project demonstrates the benefits of researchers and farmers working side-byside to design and conduct formal trials of innovative practices, such as low-input and energy-saving systems and technologies. In this way, farmers use their own criteria for evaluating the potential benefits or risks of the proposed systems.

Wehopeour experience provides a model for on-farm research and extension to be used in areas with similar agroclimatic and socioeconomic conditions, benefiting other resource-poor farm workers and farmers who have the talent and ambition to be productive and successful producers.

Miguel A. Altieri is Associate Professor and Associate Entomologist, Division of Biological Control, UC Berkeley; Javier A. Trujillo is Assistant Professor, Colegio de Post Graduados, Chapingo, Mexico; Marta A. Astier is Graduate Student, Department of Soil Science, U.C. Berkeley; P. L. Gersper is Associate Professor and Associate Pedologist, Department of Soil Science, UC Berkeley; and Wilhelmus Bakx is Graduate Student, Department of Soil Science, UC Berkeley.

Support from Richard Amon, California Energy Commission's Small Farm Energy Assistance Program; the Jessie Smith Noyes Foundation, New York; the By-Products Division of Foster Farms, Inc.; and the College of Natural Resources at UC Berkeley are greatly appreciated. C. P. Zachariadis, Executive Director, Association of Community Based Education, Washington, D.C., M. Gonzales, Agronomist, Rural Development Center, Salinas, and Maritza Muñoz, student, Department of Soil Science, U.C. Berkeley provided valuable collaboration in various aspects of the project.

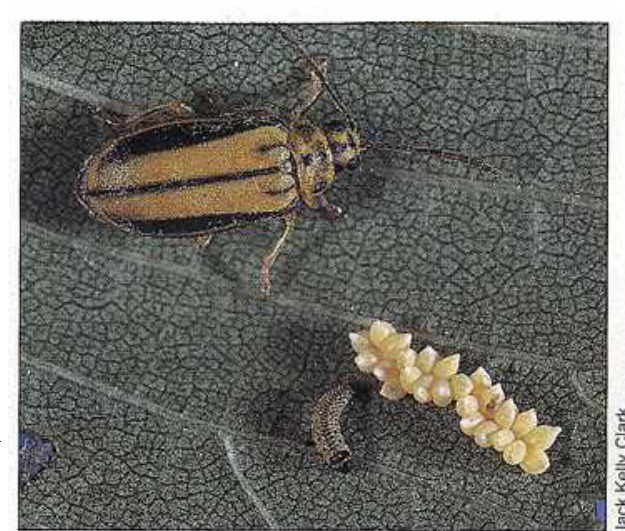

Above: Elm leaf beetle (ELB) adult, egg cluster and early instar larva.

Right: ELB prepupae and pupae, which often collect in huge numbers at the tree base.

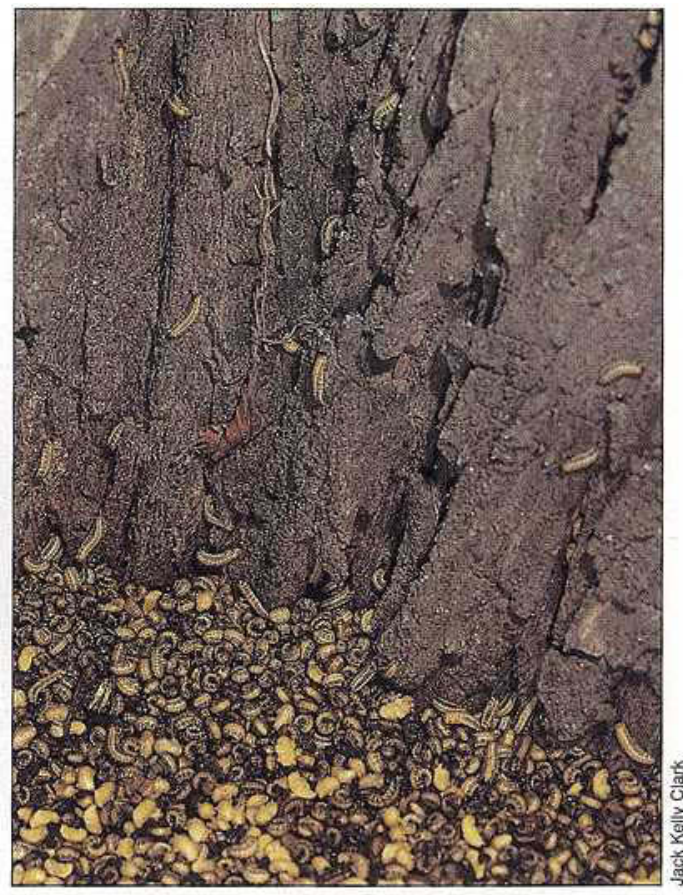

\title{
Treatment of destructive elm leaf beetle should be timed by temperature
}

\author{
Steve H. Dreistadt $\square \quad$ Donald L. Dahlsten $\square \quad$ David L. Rowney \\ Susan M. Tait $\square$ Glen Y. Yokota \ William A. Copper
}

\section{Elm leaf beetle control efforts in northern California can be effec- tively timed using temperature monitoring. Two available control methods are a new biological in- secticide, and an insecticide ap- plied as a bark band. Both meth- ods help preserve the beetle's natural enemies.}

The third most destructive urban forest insect in the western United States, elm leaf beetle (Xanthogaleruca luteola) can cause serious defoliation. In California, it is the most commonly treated pest on an estimated 2.5 million elms. Elm leaf beetle (ELB) is often managed by applying broad-spectrum insecticides to plant leaves, but these applications are expensive, can cause secondary pest outbreaks, and are increasingly unpopular with the public. We have been investigating effective, selective ELB management tools.

ELB was accidentally introduced from Europe to the United States in the 1830s and was first reported in California in the 1920s Adults overwinter in sheltered locations, such as under bark or in buildings, and emerge in the spring to lay eggs on elm foliage shortly after leaves burst. After the three larval instars have fed in the canopy, the mature larvae crawl down the trunk to pupate around the tree base. ELB has one or two generations a year in the 3,000-footelevation or higher communities in Lassen, Modoc, and Shasta Counties in northeastern California, two to three generations in the Sacramento Valley and coastal mountain valleys of northern California, and three or more generations in southern California.

\section{Biological control}

Entomologists haveestablished threeELB parasites in California. Parasitization by Erynniopsis antennata, a small, black tachinid fly, sometimes exceeds $40 \%$ and helps to reduce beetle populations. The oblong, dark reddish pupae of Erynniopsis can be seen during the summer among the greenish beetleprepupaeand yellowish pupaearound the tree base. Tetrastichus brevistigma, a small wasp that emerges from beetle pupae, is less 


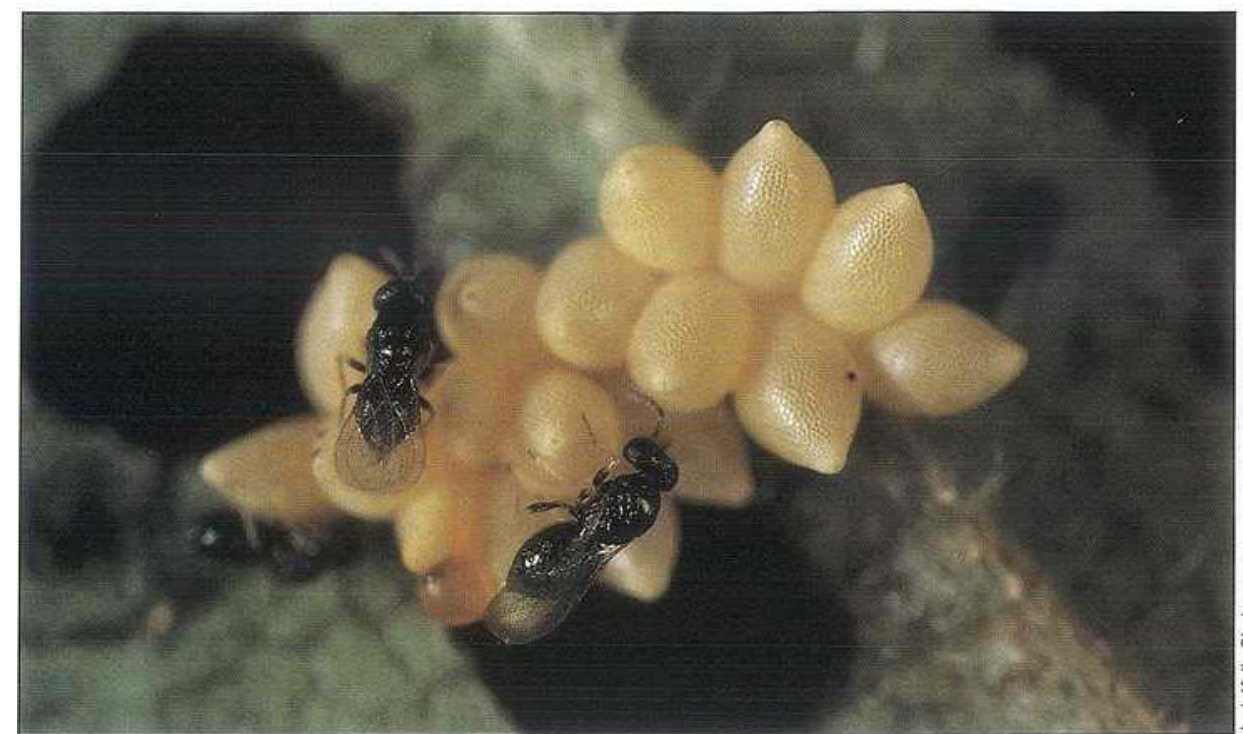

ELB egg parasites, Tetrastichus gallerucae, on ELB egg cluster.

common and apparently unimportant in California

We are introducing and studying Tetrastichus gallerucae, a parasite of ELB eggs that is established in southern California, Ohio, and now in northern California at Marysville. Biological controls alone have not yet provided adequate beetle control, but they may be more effective if combined with other methods we are researching

\section{Timing Beetle Controls}

Most pest control actions are effective against only certain insect lifestages. Because the rate of insect development depends on temperature, we have been investigating temperature monitoring as a method of timing control actions. From 1986 through 1989, we sampled beetles and damage on an average of three to four English elms (Ulmus procera) or Siberian elms (Ulmus pumila) in each of 9 to 11 locations per year in Butte, Colusa, Lassen, Madera, Marin, Modoc, Napa, Sonoma, Mendocino, Shasta, Sutter, and Yuba Counties. We examined 34 to 40 branch terminals, each 1 foot long, on each tree every 1 to 2 weeks from spring through summer. We correlated the maximum density of each lifestage with local temperatures.

Insects do not feed or develop below a "threshold temperature," which for ELB is about $52^{\circ} \mathrm{F}$. Temperatures above this threshold are monitored in units called degree-days. Degree-days for each day are estimated by subtracting the threshold temperature from the average daily temperature for that date. Monitoring degreedays helps to eliminate the guesswork or prolonged sampling otherwise required to determine when specific life stages of the pest are most abundant. For example, we want to know when eggs are most abundant because we are using the magnitude of this early-season egg peak to try to predict the extent of late-season defoliation. The calendar date of the first generation ELB egg peak in northern California varies from early April to mid-June depending on the location and weather, but occurs at between 370 and 600 degree-days above $52^{\circ} \mathrm{F}\left(\mathrm{DD}_{52} \mathrm{OF}_{\mathrm{F}}\right)$ accumulated from March 1, which is about a 4week period(see fig. 1).

If a foliar insecticide application is planned, spraying at about $700 \mathrm{DD}_{52^{\circ} \mathrm{F}}$ ac-
TABLE 1. Location, number, and species of eim trees treated in California with a single annual application of carbaryl to bark as a band during May or June, 1986-89

\begin{tabular}{lccc}
\hline \hline Location & $\begin{array}{c}\text { Treatment } \\
\text { year(s) }\end{array}$ & $\begin{array}{c}\text { Species } \\
\text { of elm* }\end{array}$ & $\begin{array}{c}\text { Number } \\
\text { of trees }\end{array}$ \\
\hline Adin & 1987 & $\mathrm{E}$ & 5 \\
Chowchilla & 1988,1989 & $\mathrm{E}$ & 40 \\
Fall River Mills & 1986,1987 & $\mathrm{~S}$ & 7 \\
Robbins & 1988 & $\mathrm{E}$ & 29 \\
St. Helena & 1986,1987 & $\mathrm{E}$ & 3 \\
Susanville & 1986,1987 & $\mathrm{~S}$ & 5 \\
Susanville & 1989 & & 32 \\
\hline
\end{tabular}

cumulated from March 1 coincides with the peak density of first generation first- and second-instar larvae in northern California. Because of field variation in development times, and because beetles are not always abundant, foliage should be inspected regularly to confirm the need for, and exact timing of, treatment.

Application timing is especially critical for Bacillus thuringiensis (Bt) variety san diego or tenebrionis. We are evaluating this new biological insecticide, recently registered for ELB control in California. This Bt kills young ELB larvae but not natural enemies. We applied $\mathrm{Bt}$ at 3 locations in Yuba and San Luis Obispo Counties in 1989 and 1990, and ourstudies continue. We found that because of the short persistence of $\mathrm{Bt}$ and the prolonged hatch of beetle eggs, more than one application may be needed to reduce high populations. To be effective, foliage must be thoroughly sprayed during warm, dry weather when young larvae are first observed.

Current temperature data for timing control actions in your area can be obtained from the UC's Statewide IPM Project computer system (IMPACT) or you can use temperatures you record or obtain from the local newspaper. IMPACT provides an easy tousemenu selection program for calculating degree-days using virtually any microcomputer equipped with a telephone modem. Copies of a degree-day program for IBMcompatible microcomputers, free computer access accounts and instructions for using IMPACT can be obtained from the IPM Implementation Group at UC Davis.

We employed IMPACT's "single sine wave" method of calculating degree-days. To time treatments in northern California,

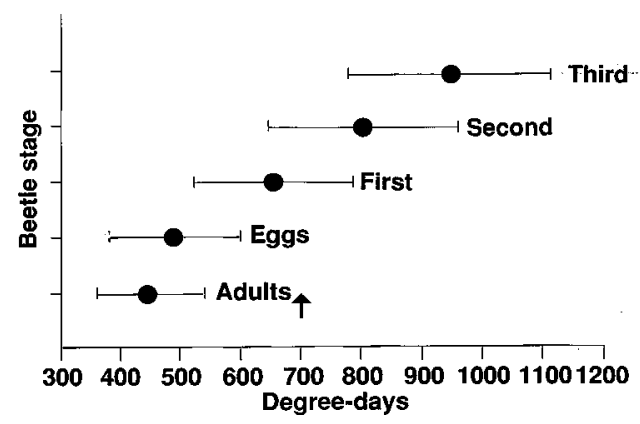

Fig. 1. The period of maximum (mean $+1-$ standard deviation) density of first generation elm leaf beetle adults and larvae (first, second, and third instars) during 1986 and 1987, and eggs during 1986-1988, at 5-11 locations per year in northern California pooled, calculated in degree-days above $52^{\circ} \mathrm{F}$ accumulated since 1 March. The arrow indicates approximately when to apply a foliar insecticide to coincide with the peak density of first generation first and second instar larvae combined, and when to apply insecticide bands prior to larvae migrating down the trunk. 
add the degree-days for each day beginning March 1 calculated with the computerized sine wave method.

\section{Insecticide bark banding}

We alsoevaluated insecticideapplication to elm bark to reduce ELB populations. A hand pump sprayer, or a hydraulic sprayer at low pressure, was used to apply carbaryl (Sevin sprayable liquid) at the labeled rate for elm bark beetles. Approximately onehalf gallon per tree of this $2 \%$ activeingredient solution was applied to about a 2-foot-wide area encircling the trunk approximately 8 to 10 feet above ground, or around the first main branch crotch. A single application to bark was made each spring before firstgeneration beetle larvae crawled down the trunk to pupate at the tree base.

The time for insecticide banding in northern California varies from early May to late June depending on the site, but approximately coincides with the peakdensity of first and second instar larvae, combined (see fig. 1). We treated groups of elms for either 1 year or 2 years, monitoring beetles and damage on treated and untreated elms at each location (see table 1). From some groups threetrees were sampled, from other groups four. Average leaf damage (skeletonization plus missing leaf area) on each of 34 to 40 samples per tree was estimated in increments of $10 \%$ by visual comparison with illustrations of elm-shaped leaves of measured defoliation.

Although no aesthetic injury level for beetle defoliation was established, banding

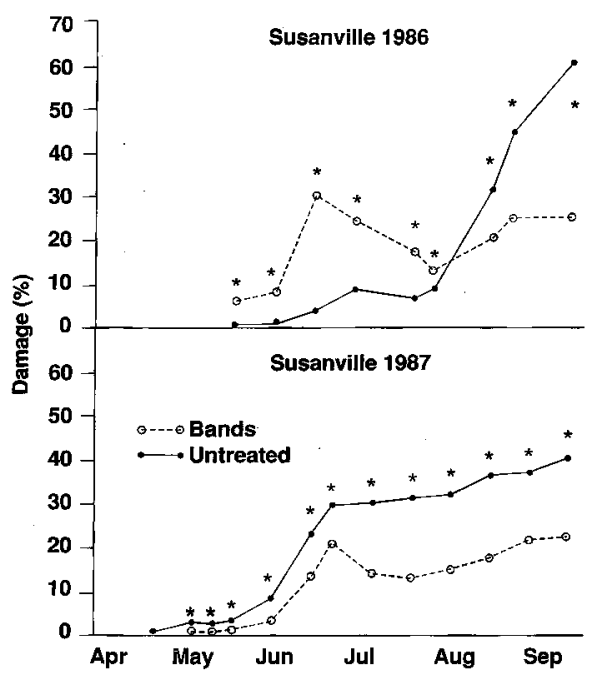

Fig. 2. Mean percentage damage to Siberian elms receiving insecticide applications to bark or untreated in Susanville, California, in 1986 and 1987. Asterisks indicate dates when damage was significantly different $(P<0.0005)$ between treatment and control trees according to the Statistical Analysis System general linear models procedure. apparently provided satisfactory ELB control during the season of treatment on Siberian elms in Susanville (fig. 2) and Fall River Mills (fig. 3). The damage on banded trees during the first or second year of application did not exceed $25 \%$ to $35 \%$, in comparison with $35 \%$ to $65 \%$ damage on untreated trees. Compared to a broad-spectrum foliar insecticide application for ELB control, bark banding reduces the treatment cost, environmental contamination, and adverseeffect on natural enemies.

Ourfinding that a single banding controls ELB during that season on Siberian elm in northeastern California differs from the findings of researchers in Los Angeles County who found no beetle control from a single season of carbaryl bark banding of Siberian elm. This may be because of environmental differences in the south where ELB has more generations.

We did not obtain satisfactory control from 1 or 2 consecutive years of banding English elms with high beetle populations. Because overwintering adults fly to the canopy and lay eggs, first generation beetle populations or damage are not reduced by that season's banding. English elms suffered much damage during the first ELB generation while Siberian elms did not, in part because Siberian elm is less susceptible to ELB damage. Beetles may also haveflown to banded trees from nearby untreated elms.

Research by others on non-Siberian elm species in the San Francisco Bay area found that bark banding groups of elms over several years reduces damage, but little control

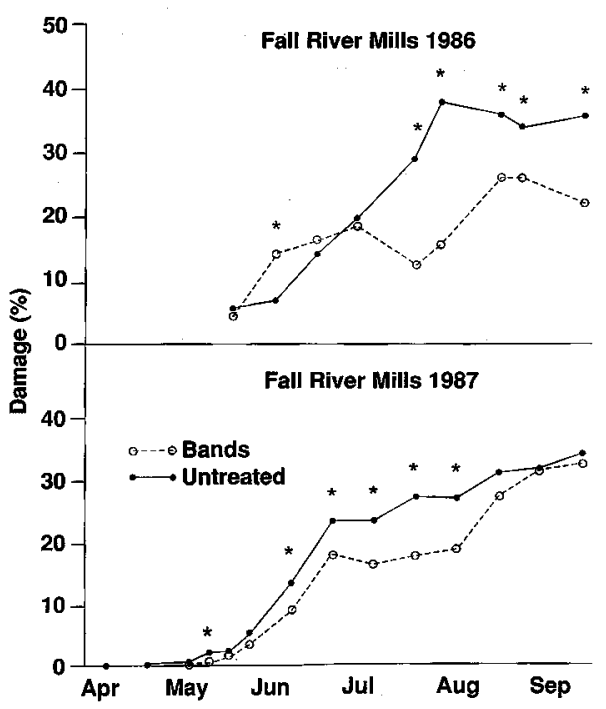

Fig. 3. Mean percentage damage to Siberian elms receiving insecticide applications to bark or untreated in Fall River Mills, California, in 1986 and 1987. Asterisks indicate dates when damage was significantly different $(P<0.0005)$ between treatment and control trees according to the Statistical Analysis System general linear models procedure.

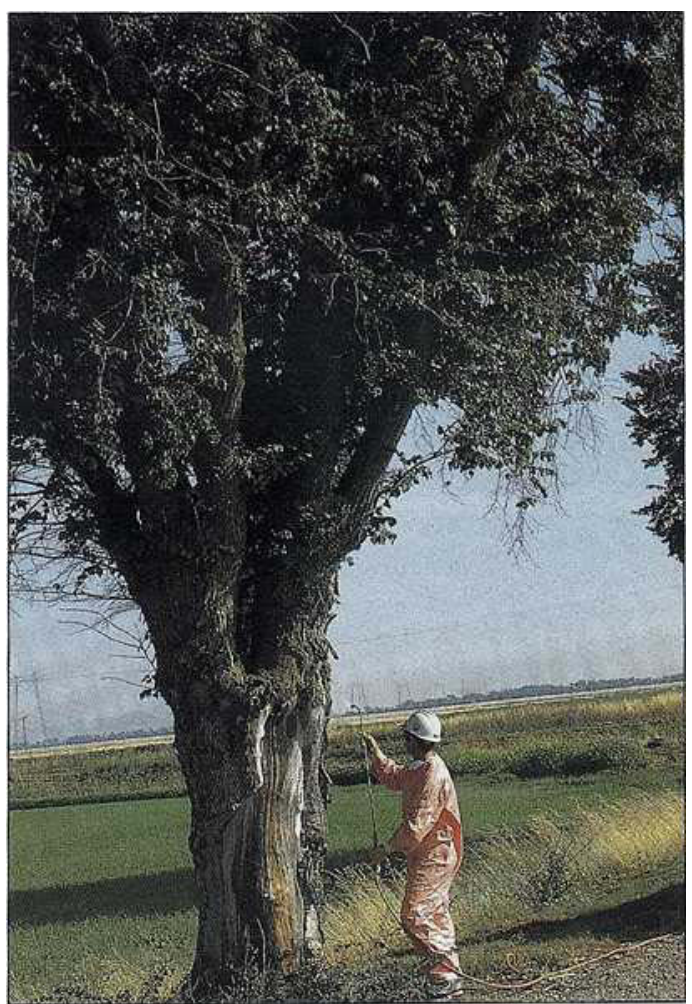

Insecticide applied to bark will control ELB lar vae migrating down the trunk to pupate at the base of the tree.

should be expected during the first year. If springELB populations arehigh, be prepared to accept damage or employ another, preferably selective, control. Banding alone, if conducted during several consecutive years on all nearby elms, may then provide adequate control. Regardless of the method employed, control actions against the target life stage can be timed in northern California by monitoring degree-days.

Steve $H$. Dreistadt is Senior Writer with the Statewide IPM Project, UC Davis, and former Research Entomologist with the Division of Biological Control, UC Berkeley. Donald L. Dahlsten is Professor of Entomology, and David L. Rowney, Susan M. Tait, Glen Y. Yokota, and William A.Copper are StaffResearch Associates, Division of Biological Control, UC Berkeley.

Theauthorsappreciate the assistance of Robert F. Luck, UC Riverside, William W. Barnett and John P. Studdert, Area IPM Farm Advisors in Fresno and Sutter-Yuba Counties, respectively, and Beverly Gingg, San Luis Obispo County Department of Agriculture. Stephen Scott, California Department of Forestry and Fire Protection, and Laurence R. Costello, San Mateo County Cooperative Extension, provided information on their research. Research funding was provided by the University of California's Elvenia J. Slosson Endowment for Ornamental Horticulture and Statewide IPM Project, and the California Departments of Forestry and Fire Protection, Transportation, and Food and Agriculture. 